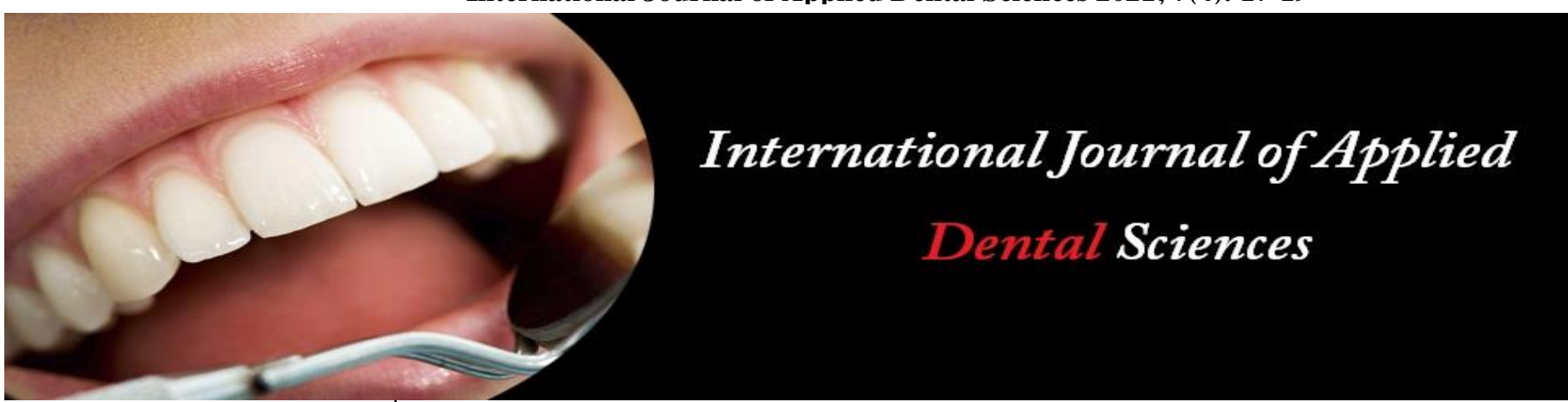

ISSN Print: 2394-7489

ISSN Online: 2394-7497

IJADS 2021; 7(4): 17-19

(C) 2021 IJADS

www.oraljournal.com

Received: 13-08-2021

Accepted: 15-09-2021

Dr. Shambhu Sharan Yadav Department of Oral Medicine \& Radiology, Dayananda Sagar College of Dental Sciences,

Bengaluru, Karnataka, India

Anela Thomas

Department of Oral Pathology \& Microbiology V.S. Dental College \& Hospital, Bengaluru,

Karnataka, India
Corresponding Author: Dr. Shambhu Sharan Yadav Department of Oral Medicine \& Radiology, Dayananda Sagar College of Dental Sciences,

Bengaluru, Karnataka, India

\section{Peripheral ossifying fibroma of posterior maxilla: A case report with a brief review}

\section{Dr. Shambhu Sharan Yadav and Anela Thomas}

DOI: $\underline{\text { https://doi.org/10.22271/oral.2021.v7.i4a.1346 }}$

\section{Abstract}

Focal gingival growth is one of the most commonly encountered lesions in the oral cavity and it is considered a non-neoplastic reactive lesion. These lesions include pyogenic granuloma, irritational fibroma, peripheral giant cell granuloma, and peripheral ossifying fibroma. This paper presents a case of peripheral ossifying fibroma in a 24 years old male patient, with an accurate diagnosis, satisfactory clinical management, and follow-up.

Keywords: peripheral ossifying fibroma, irritational fibroma, pyogenic granuloma

\section{Introduction}

Numerous types of localized reactive lesions, including fibrous hyperplasia, pyogenic granuloma, peripheral giant cell granuloma, and peripheral ossifying fibroma, may occur on the gingiva. These lesions can be provoked by irritants such as trauma, microorganisms, plaque, calculus, faulty restorations, or ill-fitting dental prosthesis ${ }^{[1,3]}$.

Peripheral ossifying fibroma (POF) is a relatively common non-neoplastic gingival growth and most frequently originates from the interdental papilla. POF frequently manifests as an exophytic, ulcerated mass attached to the interdental gingiva, with clinical features similar to other extraosseous lesions. Some of these lesions may be misdiagnosed as a pyogenic granuloma or fibrous hyperplasia of peripheral giant cell granuloma ${ }^{[2]}$.

The definite diagnosis is established through histological analysis, which reveals the fibrous proliferation associated with the formation of mineralized products in a focal area ${ }^{[4]}$.

The purpose of this article is to highlight a case report of peripheral ossifying fibroma in a 24 years old male patient, its diagnosis, and successful management.

\section{Case report}

A male patient aged 24 years old reported to the Department of Oral Medicine and Radiology with the chief complaint of painless swelling in his upper right gum for one year. The patient had noticed the swelling one year before and had gradually increase in size to the present size. On further eliciting, the patient gives the history of using toothpicks after food for 3-4 years. Other associated symptoms including difficulty in chewing and occasional bleeding on provocation were present. There was no previous history of similar growth. The medical history and family history were non-contributory. On general physical examination, the patient was fully conscious, well oriented, well-nourished with a normal gait and erect posture. Vital signs were under normal limits. The extra oral examination did not reveal any abnormality. Intraoral examination revealed, erythematous, pedunculated, solitary, well define, oval-shaped gingival growth, measuring approximately $10 \times 5 \mathrm{~mm}$ in size, extending mesiodistally from the distal aspect of 14 to the mesial aspect of 16 and cervico-occlusally from marginal gingiva of 14,15 up to the occlusal plane. On palpation, the growth was non-tender, mobile, firm inconsistency, and no discharge of pus or blood. (Figure 1).

Based on patient history and clinical examination, the lesion was provisionally diagnosed as irrigational fibroma secondary to chronic toothpick irritation, and following differential diagnosis were considered: fibrosed pyogenic granuloma, peripheral ossifying fibroma, peripheral odontogenic fibroma, solitary fibroma, fibrosed peripheral giant cell granuloma. 
The patient was then subjected to routine complete blood counts and intraoral periapical radiograph investigation with respect of 14 and 15 . The complete blood counts were under normal limits and the intraoral periapical radiograph (figure 2) did not reveal any underlying bone involvement.

After obtaining the written consent from the patient, an excisional biopsy of the lesion was performed (figure 3) and sent for the histopathological examination (figure 4). The histopathological report revealed abundant fibroblasts, thin collagen fibers, blood capillaries, and inflammatory cells, as well as a few irregular calcified masses suggestive of peripheral ossifying fibroma.

Based on the clinical, radiographic, and histopathological findings a final diagnosis of peripheral ossifying fibroma was made. There was on regular follow-up for 6 months and no signs of recurrence. (Figure 5)

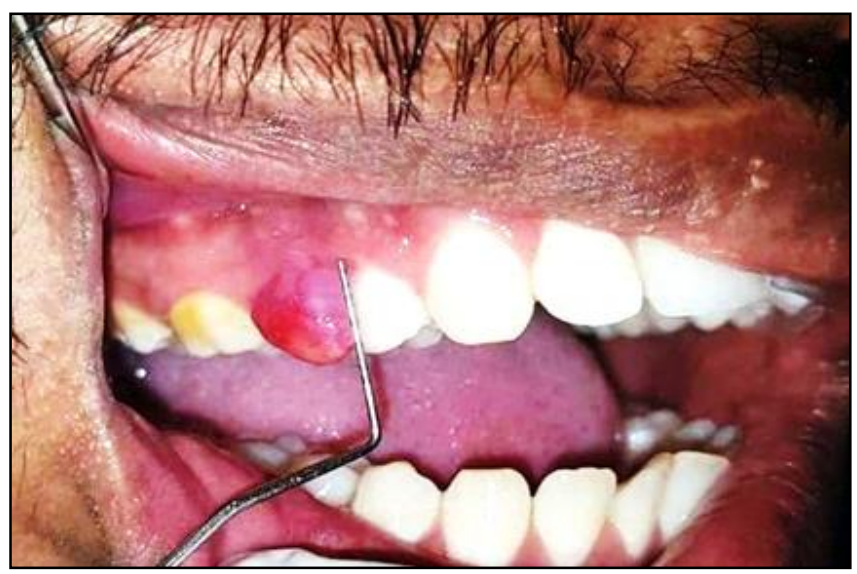

Fig 1: Oval shaped erythematous gingival growth with respect 14 \&

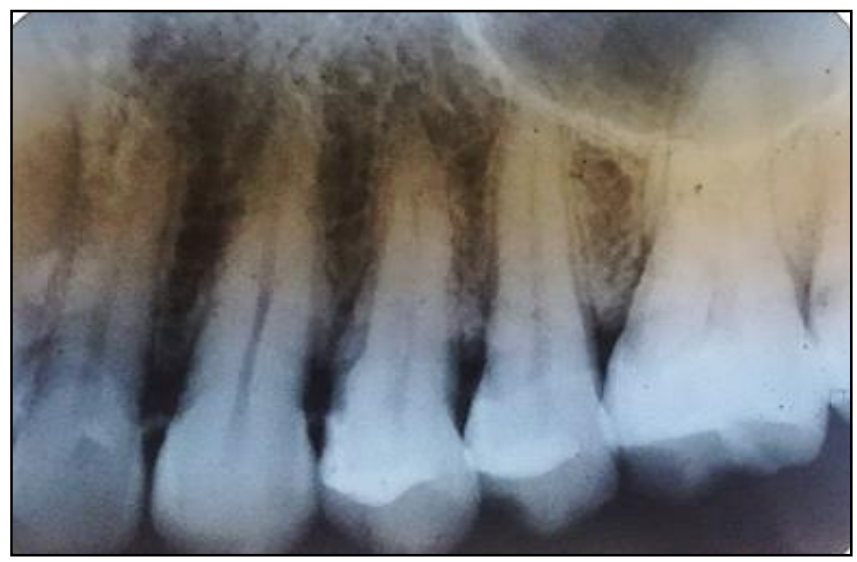

Fig 2: IOPAR of $14 \& 15$

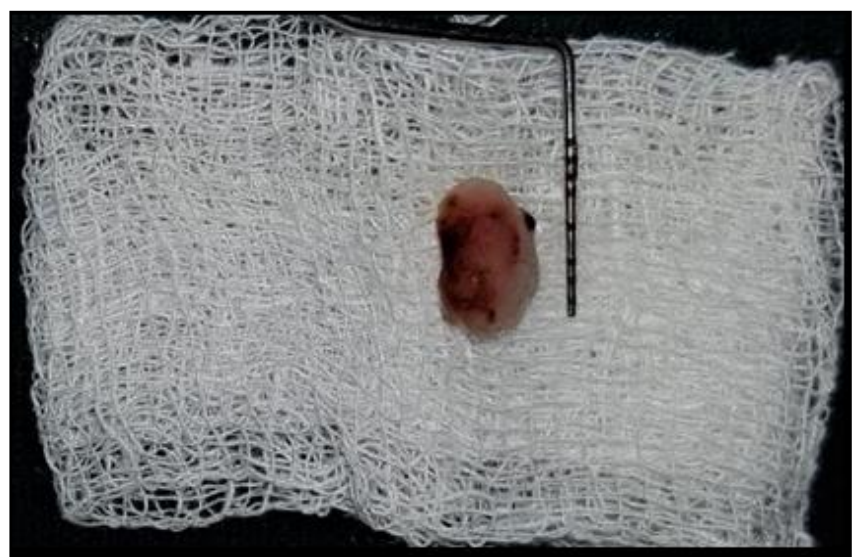

Fig 3: Excised lesion

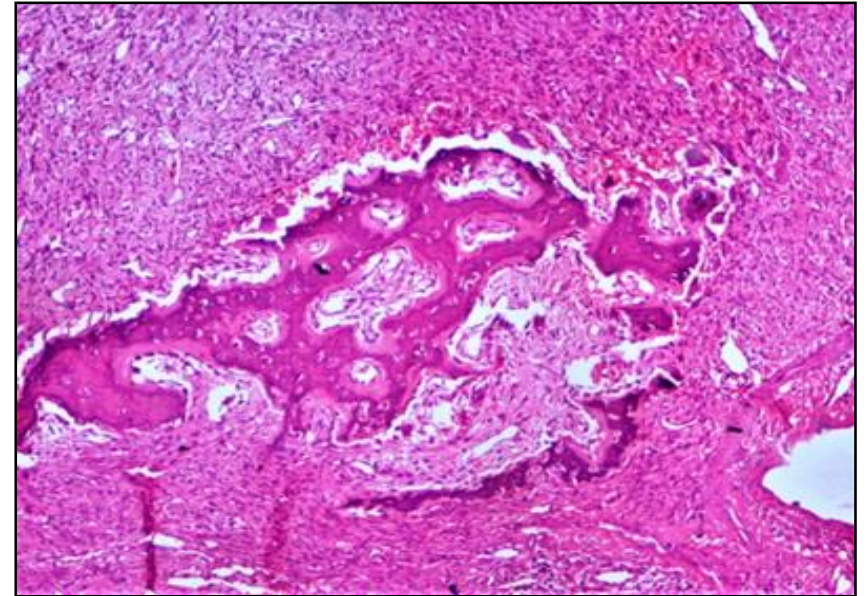

Fig 4: H\&E staining of the excised growth reveals abundant fibroblasts, thin collagen fibers, blood capillaries, and inflammatory cells, as well as a few irregular calcified masses suggestive of peripheral ossifying fibroma.

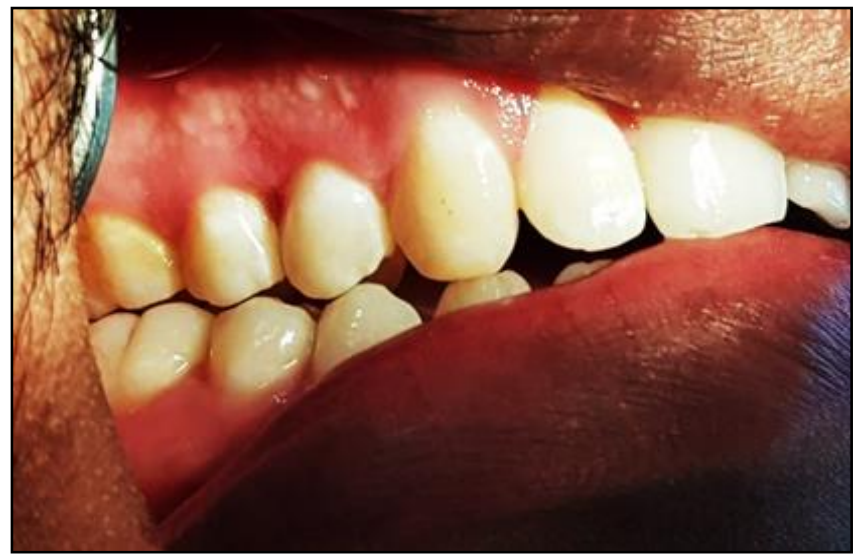

Fig 5: Follow up after 6 months.

\section{Discussion}

Peripheral ossifying fibroma is a rare reactive, non-neoplastic soft tumor-like growth that originates primarily from the interdental gingiva. Numerous term has been used to describe it over the years, including peripheral odontogenic fibroma, peripheral cemento-ossifying fibroma, peripheral cementifying fibroma, ossifying fibro-epithelial polyp, peripheral fibroma with osteogenesis, peripheral fibroma with cementogenesis, peripheral fibroma with calcification, fibrous epulis, calcifying or ossifying fibrous epulis, calcifying fibroblastic granuloma ${ }^{[2,5]}$.

Peripheral ossifying fibroma was initially described by Shepherd in 1844 as alveolar exostosis. In the year 1972, Eversol and Robin coined the term peripheral ossifying fibroma. POF is more common in younger people, with female predominance. It is more prevalent in the maxillary arch, with the majority occurring anterior to the molar region, and comprises about $9 \%$ of all gingival growth and $2 \%$ of all oral tumors ${ }^{[6]}$.

The exact etiopathogenesis of peripheral ossifying fibroma is still unknown. Because of clinical as well as histopathological similarity to pyogenic granuloma, some researchers believed that peripheral ossifying fibroma develops secondary to fibrosis of granulation tissue. Additionally, because of its predilection for females and particularly in the second decade of life, hormones influences may play a significant role ${ }^{[7]}$.

The most widely accepted histogenesis is an inflammatory proliferation of the periosteum or periodontal ligament. It is believed that the inflammatory reaction is triggered by 
damage caused by local factors such as plaque, calculus, faulty dental restoration, or ill-fitting prosthesis. This is supported by the fact that they only appear in the gingiva and there is histomorphological evidence of oxytalan fibers within the mineralized matrix ${ }^{[7]}$.

In the present case, the patient had a habit of using toothpicks after food which may have triggered the onset of the lesion.

Clinically, POF is a slow-growing, solitary, pedunculated, or sessile, nodular mass that typically develops from the interdental gingiva. The surface of the lesion is typically, but not always ulcerated. The color of the lesion may vary from pink to reddish and $1-2 \mathrm{~cm}$ in size, but cases larger than $2 \mathrm{~cm}$ have also been reported ${ }^{[4]}$.

In most cases, the teeth are unaffected, but in rare cases, it may cause pathological migration. Mobility as well as a delay in eruption of the permanent tooth ${ }^{[4]}$.

In the present case, the lesion was solitary, pedunculated, erythematous, size less than $2 \mathrm{~cm}$ and appears to originate from the interdental papilla.

POF is often solitary; however, on rare occasions, they might be multicentric and associated with the condition such as nevoid basal cell carcinoma, multiple endocrine neoplasia-II, Neurofibromatosis, and Gardener syndrome ${ }^{[8]}$.

Radiographically, the lesion does not show any obvious bone involvement in the periapical radiograph. However, in rare cases, there is a possibility of superficial erosion of bone ${ }^{[9]}$.

In the present case, the Intraoral Periapical Radiograph did not reveal any underlying bone involvement.

Histologically, POF is characterized by the following features such as intact or ulcerated stratified squamous surface epithelium, benign fibrous connective tissue with an abundant number of fibroblast, mineralized material consisting of mature, lamellar, or woven osteoid, cementum like material or dystrophic calcification, and acute or chronic inflammatory cells in the lesion ${ }^{[10]}$.

In the present case, the histopathological report revealed abundant fibroblasts, thin collagen fibers, blood capillaries, and inflammatory cells, as well as a few irregular calcified masses suggestive of peripheral ossifying fibroma.

The treatment of POF is complete excision of the lesion because POF has a high rate of recurrence around $8-16 \%$. Repositioned flaps or connective tissue grafts may be necessary in extremely damaged cases to restore gingival defects ${ }^{[7]}$.

In this case, the lesion was completely excised under local anesthesia and was followed up for 6 months with no signs of recurrence.

\section{Conclusion}

POF is a progressive lesion with a high recurrence rate. POF should be identified clinically, radiographically, and histologically as soon as possible for a better treatment outcome. To prevent a recurrence, the lesion should be completely excised along with the removal of all irritants and etiological factors.

\section{References}

1. Bhaskar SN, Jacoway JR. Peripheral fibroma and peripheral fibroma with calcification: Report of 376 cases. J Am Dent Assoc 1966;73:1312-20.

2. Eversole LR, Rovin S. Reactive lesions of the gingiva. J Oral Pathol 1972;1:30-8.

3. Gardner DG. The peripheral odontogenic fibroma: An attempt at clarification. Oral Surg Oral Med Oral Pathol 1982;54:40-8.
4. Neville BW, Damm DD, Allen CM, Bouquot JE. Soft tissue tumors. Oral and maxillofacial pathology. 3rd ed. Missouri: Elsevier. P 521-3.

5. Zain RB, Fei YJ. Fibrous lesions of the gingiva: a histopathological analysis of 204 cases. Oral Surg Oral Med Oral Pathol 1990;70:466-70.

6. Mohiuddin K, Priya NS, Ravindra S, Murthy S. Peripheral ossifying fibroma. J Indian Soc Periodontol. 2013;17(4):507-509.

7. Sudhakar S, Praveen Kumar B, Prabhat MPV. Peripheral Ossifying Fibroma. Online J Health Allied Scs. 2009;8(3):17

8. Kumar SKS, Ram S, Jorgensen MG, Shuler CF, Sedghizadeh PP. Multicentric peripheral ossifying fibroma. J Oral Sci 2006;48:239-43.

9. Kfir Y, Büchner A, Hansen LS. Reactive lesions of the gingiva - a clinicopathologic study of 741 cases. J Periodontol 1980;2013:655-61.

10. Yadav R, Gulati A. Peripheral ossifying fibroma: a case report. J Oral Sci 2009;51:151-4. 